of males and females achieving remission or low disease activity according to gender (figure 1A) nor in terms of reduction of TJ, SJ and PGA; only pain decreased significantly more in male than in female patients at both timepoints (figure 1B).

Conclusion: In RA patients treated with JAK inhibitors, even if the effect of JAKi on pain seems to be more relevant in male than in female, gender seems not to influence the overall clinical response, allowing men and women the same probability of reaching the therapeutic target

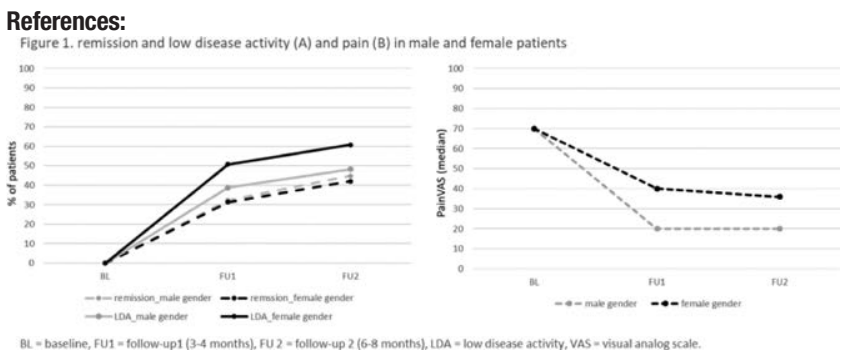

Disclosure of Interests: Francesca Romana Spinelli Grant/research support from: Pfizer, Speakers bureau: Lilly, BMS, Celgene, Maria Sole Chimenti: None declared, Marta Vadacca: None declared, Cristina lannuccelli: None declared, Paola Conigliaro: None declared, Silvia Laura Bosello: None declared, Fulvia Ceccarelli: None declared, Cristina Garufi: None declared, Giulia Raffone: None declared, Paola Di Noi: None declared, Dario Bruno: None declared, Antonella Afeltra: None declared, Roberto Perricone: None declared, fabrizio conti Speakers bureau: BMS, Lilly, Abbvie, Pfizer, Sanofi, Elisa Gremese Speakers bureau: Abbvie, BMS, Celgene, Jannsen, Lilly, MSD, Novartis, Pfizer, Sandoz, UCB DOI: 10.1136/annrheumdis-2020-eular.5978

\section{SAT0154 \\ EXAMINATION OF CYP3A5 GENOTYPE IS USEFUL FOR INTRODUCTION OF TACROLIMUS TREATMENT IN OUTPATIENTS WITH RHEUMATIC DISEASES}

S. Takahashi ${ }^{1}, 2$, S. Horibata ${ }^{2,3}$, S. Hatachi ${ }^{1}$, M. Takahashi $^{2}$, M. Katayama ${ }^{1}$, S. Mukohara ${ }^{1}$, N. Amano ${ }^{1}$, K. Yoshida ${ }^{1}$, K. Yorifuji ${ }^{2,3}$, S. Kumagai ${ }^{1,2} .{ }^{1}$ Center for Rheumatic Disease, Shinko Hospital, Kobe, Japan; ${ }^{2}$ Shinko Institute for Medical Research, Kobe, Japan; ${ }^{3}$ Department of Pharmacy, Shinko Hospital, Kobe, Japan

Background: Though several studies showed the efficacy of tacrolimus (TAC) in patients with rheumatoid arthritis (RA) in a dose-depending manner [1], the relationship between efficacy and concentration of TAC remained unclear. Genetic polymorphisms of cytochrome P450 (CYP) 3A5 were reported not only to play an important role in pharmacokinetics of TAC but also to have an influence on clinical outcomes in patients of rheumatic diseases. Several reports showed that the blood concentration of TAC in patients with a CYP3A5 *1 allele (EX, expressor) was lower than that of patients with a CYP3A5 ${ }^{*} 3{ }^{*} 3($ NEX, non-expressor) [2]

Objectives: To assess the relationship between efficacy and concentration of TAC in patients with RA, and to examine the usefulness of CYP3A5 genotype screening to detect outpatients suitable for TAC treatment.

Methods: We examined the relationship between disease activity score (DAS) 28-CRP and concentration of TAC in patients with RA. TAC was taken after the evening meal and blood samples were taken $12 \pm 4 \mathrm{~h}$ after TAC administration. Next we investigated the relationship between genotype frequencies of CYP3A5 and concentration of TAC in patients with rheumatic disease without having renal dysfunction (eGFR<60) and also investigated the influence of concomitant drugs, such as strong inhibitors of CYP3A4/5 or metabolized by CYP3A4/5, to C/D value in each NEX and EX group. The blood concentration of TAC normalized to the corresponding dose per body weight (C/D, ng/ $\mathrm{ml}$ per $\mathrm{mg} / \mathrm{kg}$ ) was analyzed according to genetic variation in CYP3A5. Furthermore we investigated the relationship between genotype frequencies of CYP3A5 and concentration of TAC in patients with rheumatic disease at first visit and second visit after starting TAC administration to assess the possibility for making rapid attainment of enough concentrations of TAC in early stage of treatment.

Results: The concentration of TAC tended to be negatively correlated with the disease activity of RA. The C/D value in the NEX group $(n=16)$ was $124.7 \pm 62.1$, which was significantly higher than that in the EX group $(n=23 ; 67.7 \pm 29.8 ; P<0.001)$. When comparing patients using concomitant drugs which are strong inhibitors of CYP3A4/5 or metabolized by CYP3A $4 / 5$ with patients not using those drugs, the each C/D value of NEX group was
$122.9 \pm 52.3(n=9)$ and $126.9 \pm 77.3(n=7)$, and that of EX group was $71.3 \pm 32.2$ $(n=12)$ and $63.8 \pm 28.0(n=11)$. There were no significant differences between these groups. In NEX group, when comparing concentration of TAC at first visit and second visit after starting TAC administration, the each concentration of TAC was $3.14 \pm 2.06 \mathrm{ng} / \mathrm{ml}$ and $3.80 \pm 2.20 \mathrm{ng} / \mathrm{ml}$ in NEX group $(n=10)$, and that of TAC was $1.82 \pm 0.82 \mathrm{ng} / \mathrm{ml}$ and $2.69 \pm 1.52 \mathrm{ng} / \mathrm{ml}(\mathrm{n}=11)$ in $E X$ group (Figure).

Conclusion: TAC showed efficacy in patients with RA in a concentration-dependent manner. EX patients may be impossible to achieve enough concentration of TAC even though using TAC of $3 \mathrm{mg} /$ day, approved dose for patients with RA in Japan, and NEX patients could make rapid attainment of enough concentrations of TAC in early stage of treatment, suggesting that we should consider induction of TAC only in NEX outpatients. Furthermore, drugs only slightly affected concentration of TAC in this study, suggesting that we can use TAC without any special attention to concomitant drugs.

References:

[1] Furst DE et al. Arthritis Rheum 2002;46:2020-28

[2] Y. Muraki et al. Exp Ther Med 2018;15:532-38.

\section{NEX patients rapidly gain higher TAC concentration than EX patients in early stage of treatment}

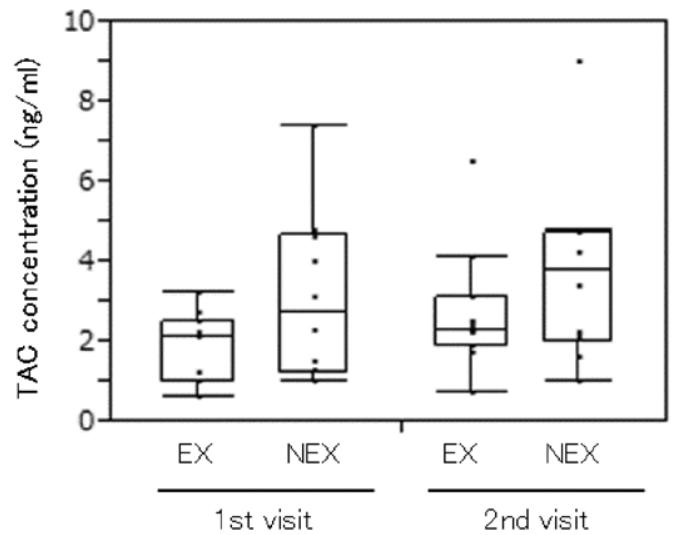

Acknowledgments: none

Disclosure of Interests: Soshi Takahashi: None declared, Shinji Horibata: None declared, Saori Hatachi: None declared, Miho Takahashi: None declared, Motoko Katayama: None declared, Saki Mukohara: None declared, Norihiko Amano: None declared, Katsuyuki Yoshida: None declared, Kennosuke Yorifuji: None declared, Shunichi Kumagai Grant/research support from: Astellas, Chugai, Mitsubishi Tanabe Co.Ltds, Consultant of: Sysmex Co.Ltd, Speakers bureau: many companies

DOI: 10.1136/annrheumdis-2020-eular.4028

\begin{tabular}{|l|l}
\hline SAT0155 & WHOLE BLOOD TRANSCRIPTIONAL CHANGES \\
& FOLLOWING SELECTIVE INHIBITION OF JANUS \\
& KINASE 1 (JAK1) BY FILGOTINIB IN MTX-NAÏVE \\
& ADULTS WITH MODERATELY-TO-SEVERELY ACTIVE \\
& RHEUMATOID ARTHRITIS (RA) (FINCH3)
\end{tabular}

P. C. Taylor' ${ }^{1}$, B. Downie' ${ }^{2}$, E. Elboudwarej' ${ }^{2}$ S. Kim², A. Hertz², A. M. Mirza², J. Siegel ${ }^{2}$, R. E. Hawtin ${ }^{2}$, J. Liu' ${ }^{2}{ }^{1}$ University of Oxford, Botnar Research Centre, Nuffield Dept Orthopaedics, Rheumatology and Musculoskeletal Sciences, Oxford, United Kingdom; ${ }^{2}$ Gilead Sciences Inc., Foster City, United States of America

Background: Filgotinib (FIL), an oral selective JAK1 inhibitor, has shown efficacy and safety in multiple phase 3 studies in adults with moderately-to-severely active rheumatoid arthritis (RA). We have previously described the molecular response to FIL in large-scale RNA sequencing studies of gene expression in other RA populations ${ }^{1-3}$ and conducted a similar study in methotrexate (MTX)-naïve RA patients (pts) (FINCH3).

Objectives: Identify gene transcripts and biological pathways associated with RA and those altered in response to FIL treatment.

Methods: MTX-naïve RA pts who were enrolled in FINCH3 (ClinicalTrials.gov NCT02886728) received a stable dose of MTX with placebo (PBO+MTX), FIL $200 \mathrm{mg}$ alone (FIL 200mg monotherapy), or one of two doses of FIL once daily (QD) together with MTX (FIL 100mg+MTX, FIL 200mg+MTX). Whole blood samples were collected from pts using PAXgene tubes at baseline, week 4, 
week 12, and week 24. RNA from these samples was extracted and sequenced on the Illumina HiSeq 2500 platform following globin RNA depletion. Correlations between baseline gene expression and disease measurements were performed using Spearman's rank partial correlation to account for covariates. Differentially expressed genes (DEGs) were identified using voom-limma. Biological pathway analyses were performed on v6.1 of the Molecular Signature Database using single sample gene set enrichment analysis (GSEA) with the focus on immune signaling pathways from the Kyoto Encyclopedia of Genes and Genomes (KEGG). A false-discovery rate of $5 \%$ was applied for all analyses.

Results: Differential gene expression analyses comparing baseline samples with after-treatment samples revealed rapid onset of transcriptional changes in FIL-treated pts, most notably for the two FIL 200mg arms. Fewer DEGs were observed at all timepoints in $\mathrm{PBO}+\mathrm{MTX}$ treated patients with a peak number at week 24, an observation consistent with the clinical response kinetics of MTX. ${ }^{4}$ Up to $3 x$ as many significant DEGs were observed in the FIL 200mg+MTX arm compared to the FIL 100mg+MTX arm, a finding consistent with the superior clinical efficacy of the FIL 200mg dosage. As with other FIL clinical trial RNA-seq studies and consistent with the selective MoA of FIL, JAK-STAT pathway-induced genes SOCS2 and CISH were significantly downregulated across FIL treatment arms and timepoints, but not for PBO+MTX. RA disease activity-associated genes ${ }^{2-3}$ FAM20A and METTL7B were significantly reduced at all timepoints in FIL-treated pts, but only at week 24 in PBO+MTX pts. While no significant changes in KEGG immune signaling pathways were observed in the PBO+MTX arm, a dose-dependent effect on pathway modulation was observed in the FIL arms, including reductions in JAK-STAT, toll-like receptor, chemokine, and RIG-I like receptor signaling.

Conclusion: More rapid and sustained changes of transcriptional activity in the whole blood transcriptional profile of RA pts after FIL treatment were found compared to PBO+MTX. Dose-dependent changes were observed in FIL-treated pts, most notably in the KEGG JAK-STAT signaling pathway. These observations confirm an inhibition of JAK-STAT signaling by FIL and are consistent with the observed clinical efficacy of FIL in these pts.

References:

[1] Taylor PC, et al. (EULAR 2018). http://dx.doi.org/10.1136/ annrheumdis-2018-eular.3759

[2] Taylor PC, et al. (ACR 2018). https://doi.org/10.1093/rheumatology/kez105.001

[3] Taylor PC, et al. (EULAR 2019). http://dx.doi.org/10.1136/ annrheumdis-2019-eular.2509

[4] Taylor PC, et al. J Clin Med. 2019;8(4): pii: E515. doi: 10.3390/jcm8040515 Acknowledgments: This study was funded by Gilead Sciences, Inc. Editorial support was provided by Fishawack Communications Inc and funded by Gilead Sciences, Inc.

Disclosure of Interests: Peter C. Taylor Grant/research support from: Celgene, Eli Lilly and Company, Galapagos, and Gilead, Consultant of: AbbVie, Biogen, Eli Lilly and Company, Fresenius, Galapagos, Gilead, GlaxoSmithKline, Janssen, Nordic Pharma, Pfizer Roche, and UCB, Bryan Downie Shareholder of: Gilead Sciences Inc., Employee of: Gilead Sciences Inc., Emon Elboudwarej Shareholder of: Gilead Sciences Inc., Employee of: Gilead Sciences Inc., Sam Kim Shareholder of: Gilead Sciences Inc., Employee of: Gilead Sciences Inc., Angie Hertz Shareholder of: Gilead Sciences Inc, Employee of: Gilead Sciences Inc, Amer M. Mirza Shareholder of: Gilead Sciences Inc., Employee of: Gilead Sciences Inc., Jeffrey Siegel Shareholder of: Gilead Sciences Inc., Employee of: Gilead Sciences Inc., Rachael E. Hawtin Shareholder of: Gilead Sciences Inc., Employee of: Gilead Sciences Inc., Jinfeng Liu Shareholder of: Gilead Sciences Inc., Roche, Employee of: Gilead Sciences Inc.

DOI: 10.1136/annrheumdis-2020-eular.3949

\section{SAT0156 EFFECTIVE OF BARICITINIB ON RADIOGRAPHIC PROGRESSION OF STRUCTURAL JOINT DAMAGE AT 48 WEEKS IN PATIENTS WITH RHEUMATOID ARTHRITIS IN REAL-WORLD MULTICENTER CLINICAL DATA}

E. Torikai ${ }^{1}$, Y. Hirano ${ }^{2}$, D. Suzuki ${ }^{3}$, Y. Kanayama ${ }^{4} .{ }^{1}$ Iwata City Hospital, Iwata, Japan; ${ }^{2}$ Toyohashi Municipal Hospital, Toyohashi, Japan; ${ }^{3}$ Futaba Clinic, Iwata, Japan; ${ }^{4}$ Toyota Kosei Hospital, Toyota, Japan

Background: Baricitinib (bari) is an oral Janus kinase 1 (JAK1)/JAK2 selective inhibitor that has demonstrated good efficacy in patients with rheumatoid arthritis (RA) and adequate response to conventional synthetic (cs) DMARDs in some clinical trials [1,2]. We report the efficacy and safety of bari within 24 weeks in realworld clinical data at EULAR2019.

Objectives: To evaluate the radiographic progression of structural joint damage at 48 weeks in Japanese patients with RA in real-world multicenter clinical data. Methods: We included 53 Japanese patients with RA who showed an inadequate response to csDMARDs or biologic (b) DMARDs. Patients were scheduled to receive a once-daily dose of 4 or $2 \mathrm{mg} /$ day bari as monotherapy or in combination with other csDMARDs. We divided the patients into two groups: those treated with $2 \mathrm{mg} /$ day of bari ( $2 \mathrm{mg}$-group; $\mathrm{n}=27$ ) and those treated with $4 \mathrm{mg} /$ day of bari (4-mg group; $\mathrm{n}=26$ ) throughout the observation period. Patients were allowed to decrease their predonisolone and csDMARDs combined with bari treatment if their disease activity improved. First, we evalu ated changes in CDAI and HAQ-DI after 48 weeks. Second, we evaluated the change in the van der Heijdge modified total sharp score ( $\Delta$ mTSS), erosion score $(\Delta \mathrm{ERN})$, and joint space narrowing score $(\Delta \mathrm{JSN})$. In addition, we assessed predictors for suppression of joint destruction at 48 weeks after bari treatment.

Results: The baseline characteristics of the patients were as summarized in Table 1. There were no significant differences in any items. CDAl scores significantly improved 4 weeks after the treatment. This tendency continued until the final evaluation (Table 2). At 48 weeks, remission and low disease activity rates were $37.0 \%$ and $74.1 \%$ in the 2 -mg group and $38.4 \%$ and $76.9 \%$ in the 4-mg group, respectively. Structural remission (mTSS $\leq 0.5$ ) was noted in 21 patients $(80.8 \%)$ and 21 patients $(77.8 \%)$ in 4-mg group and 2 -mg group respectively (Figure). Mean scores ( $\triangle \mathrm{mTSS}, \triangle \mathrm{ERN}$, and $\Delta \mathrm{JSN}$ ) of all patients in the 2-mg group and 4-mg groups were $(0.26,0.15$, and 0.11$),(0.30,0.17$ and 0.13$)$ and $(0.23,0.13$, and 0.10$)$, respectively (Figure). There were no significant differences in $\triangle$ mTSS scores between the two groups. A matrix metalloproteinase-3 score within the standard value at 12 weeks after the treatment was associated with a predictor for suppression of joint destruction at 48 weeks (logistic regression analysis; odds ratio $=11.6,95 \%$ confidence interval: $1.5-112.4, P=0.020)$

Table 1. Characteristics of patients at baricitinib initiation

\begin{tabular}{lccc}
\hline & 2mg-group ( $\mathrm{n}=27)$ & 4mg-group $(\mathrm{n}=26)$ & p-value \\
\hline Age (years) & $69.1(12.0)$ & $65.6(10.3)$ & 0.20 \\
Gender, female, $\mathrm{n}(\%)$ & $19(73.1)$ & $23(85.2)$ & 0.28 \\
Disease duration (years), & $9.7(10.4)$ & $5.7(7.4)$ & 0.23 \\
Prior use of biologics, (0/1/2/3) & $(18 / 6 / 2 / 1)$ & $(18 / 2 / 5 / 1)$ & ----- \\
MTX (mg/week), & $4.5(3.7)$ & $6.5(4.29)$ & 0.08 \\
PSL (mg/day) & $1.0(1.9)$ & $1.2(1.8)$ & 0.49 \\
RF, U/ml & $254(372)$ & $134(222)$ & 0.21 \\
ACPA, U/m & $152(176)$ & $133(301)$ & 0.45 \\
MMP-3 & $196(220)$ & $215(221)$ & 0.43 \\
\hline
\end{tabular}

Table 2. Serial change of clinical assessment

\begin{tabular}{lccccc}
\hline 2mg-group & Baseline & 4 week & 12 week & 24 week & 48 week \\
\hline CDAI & $22.5(9.2)$ & $7.4(7.7)$ & $6.7(6.9)$ & $6.9(6.8)$ & $6.9(6.8)$ \\
HAQ-DI & $0.88(0.51)$ & $0.45(0.47)$ & $0.53(0.58)$ & $0.56(0.56)$ & $0.56(0.56)$ \\
MMP-3 & $196(221)$ & $98.9(62.2)$ & $115(164)$ & $106(78)$ & $106(78)$ \\
4mg-group & Baseline & 4 week & 12 week & 24 week & 48 week \\
CDAI & $24.4(9.7)$ & $9.4(5.7)$ & $8.6(6.3)$ & $6.7(8.6)$ & $6.8(8.6)$ \\
HAQ-DI & $1.01(0.51)$ & $0.58(0.48)$ & $0.54(0.60)$ & $0.45(0.49)$ & $0.44(0.45)$ \\
MMP-3 & $216(222)$ & $99(62)$ & $101(123)$ & $89(72)$ & $95(81)$ \\
\hline
\end{tabular}

Figure

(a) Probability blot mTSS in 4mg-group

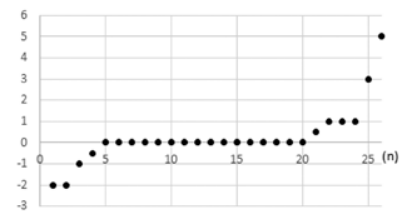

(c) Mean scores of $\triangle \mathrm{mTSS}, \triangle \mathrm{ETN}$ and $\triangle \mathrm{JSN}$

(b) Probability blot mTSS in $2 \mathrm{mg}$-group
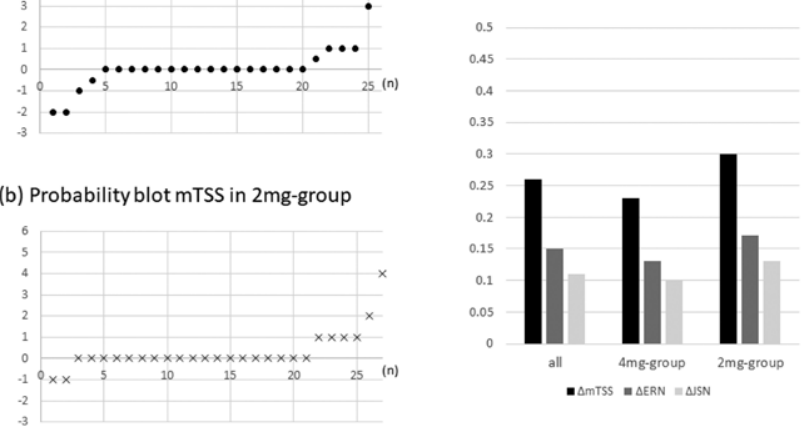

Conclusion: The data showed that bari has a favorable effect on the radiographic progression of structural joint damage regardless of its dose in a real-world clinical setting. In consideration of the risk/benefit balance, we suggest that the dose of bari could be reduced in patients with favorable disease activity. 